\title{
A dominant mutation in the gene for the Nag repressor of Escherichia coli that renders the nag regulon uninducible
}

\author{
JacQueline A. Plumbridge* \\ Institut de Biologie Physico-chimique (URA1139), 13 rue Pierre et Marie Curie, 75005 Paris, France
}

(Received 21 October 1991; revised 27 January 1992; accepted 7 February 1992)

\begin{abstract}
The gene nagC encodes the repressor for the nag regulon. A point mutation within the gene, which confers a superrepressor phenotype and makes the repressor insensitive to the inducer, $\boldsymbol{N}$-acetylglucosamine 6-phosphate, has been characterized. The mutation is semi-dominant since heterozygous diploids have reduced growth rates on glucosamine and $\boldsymbol{N}$-acetylglucosamine compared to the wild-type strain.
\end{abstract}

\section{Introduction}

The nag regulon of Escherichia coli, located at $15.5 \mathrm{~min}$ on the genetic map (Bachmann, 1990) encodes genes necessary for the uptake and degradation of the amino sugars, D-glucosamine (GlcN) and $\boldsymbol{N}$-acetyl-D-glucosamine (GlcNAc). It consists of divergent operons nagE and nagBACD (Fig. 1). nagE encodes the GlcNAcspecific transporter (EII ${ }^{\mathrm{Nag}}$ ) of the phosphoenolpyruvate-dependent phosphotransferase system (PTS) (Jones-Mortimer \& Kornberg, 1980; Lengeler, 1980; Peri \& Waygood, 1988; Rogers et al., 1988) and produces intracellular GlcNAc 6-phosphate. GlcN is primarily transported by the generic hexose transporter of the PTS, encoded by the genes manXYZ located at $40 \mathrm{~min}$, which also transports GlcNAc (Curtis \& Epstein, 1975; Erni et al., 1987; Jones-Mortimer \& Kornberg, 1980; Saris \& Palva, 1987). Expressed in the opposite direction to nag $E$ (anticlockwise) are $\operatorname{nag} B$ and $n a g A$ encoding the two enzymes which degrade GlcNAc 6-phosphate to fructose 6-phosphate: GlcNAc-6-phosphate deacetylase (nagA) and GlcN-6-phosphate deaminase (nagB) (Holmes \& Russell, 1972; Plumbridge, 1989; Vogler \& Lengeler, 1989; White, 1968). The third gene, nagC, encodes a repressor for the regulon (Plumbridge, 1991; Vogler \& Lengeler, 1989). Two binding sites for the repressor have been located in the intergenic nag $E$-nag $B$ region overlapping the $n a g E$ and $n a g B$ promoters (Plumbridge $\& \mathrm{Kolb}$, 1991). A gene for a fourth ORF, provisionally called

\footnotetext{
- Tel. 1432526 09; fax 140468331 .

Abbreviations: GlcN, D-glucosamine; GlcNAc, $N$-acetyl-D-glucosamine; PTS, phosphoenolpyruvate-dependent phosphotransferase system.
}

$n a g D$, is located downstream of the nagC gene. No function has been attributed to this gene.

Mutations preventing growth on GlcNAc were first isolated by White (1968). He characterized two alleles in detail, nagB2 and nag $A 1$. The nagB2 mutation prevented growth on both GlcNAc and GlcN while the nagA1 mutation prevented growth on GlcNAc but not GlcN. The nagAl mutation was pleiotropic; the strains were $\mathrm{Nag}^{\mathrm{S}}$, had increased levels of GlcN-6-phosphate deaminase, enhanced GlcNAc transport activity and accumulated high concentrations of GlcNAc 6-phosphate, the substrate of the deacetylase. [ $\mathrm{Nag}^{\mathrm{S}}$ is the phenomenon where the presence of GlcNAc inhibits growth on other carbon sources. This is presumably due to the accumulation of toxic levels of GlcNAc 6-phosphate which cannot be further metabolized in the nag $A$ strain (White, 1968; Bernheim \& Dobrogosz, 1970).] The same set of phenotypes are apparent with other nagA mutations, both those constructed in vitro by the insertion of antibiotic resistance cassettes, (Plumbridge, 1991) or by $\lambda$ plac Mu mutagenesis in vivo (Vogler \& Lengeler, 1989). The enhanced transport and deaminase activities of these strains are the result of endogenous induction from the accumulation of GlcNAc 6-phosphate which is the intracellular inducer of the regulon. In the presence of this phosphorylated form of GlcNAc, the repressor is prevented from binding to the operator sites of the nag $E$ nag $B$ intergenic region so that expression of the two operons is induced (Plumbridge, 1991).

White (1968) noted that the strain carrying the nagAl mutation was unstable and segregated bacteria which had lost the Nags phenotype, i.e. they became NagR. They were still $\mathrm{Nag}^{-}$but now grew slowly or not at all on GlcN, presumably due to the acquisition of secondary 
(a)
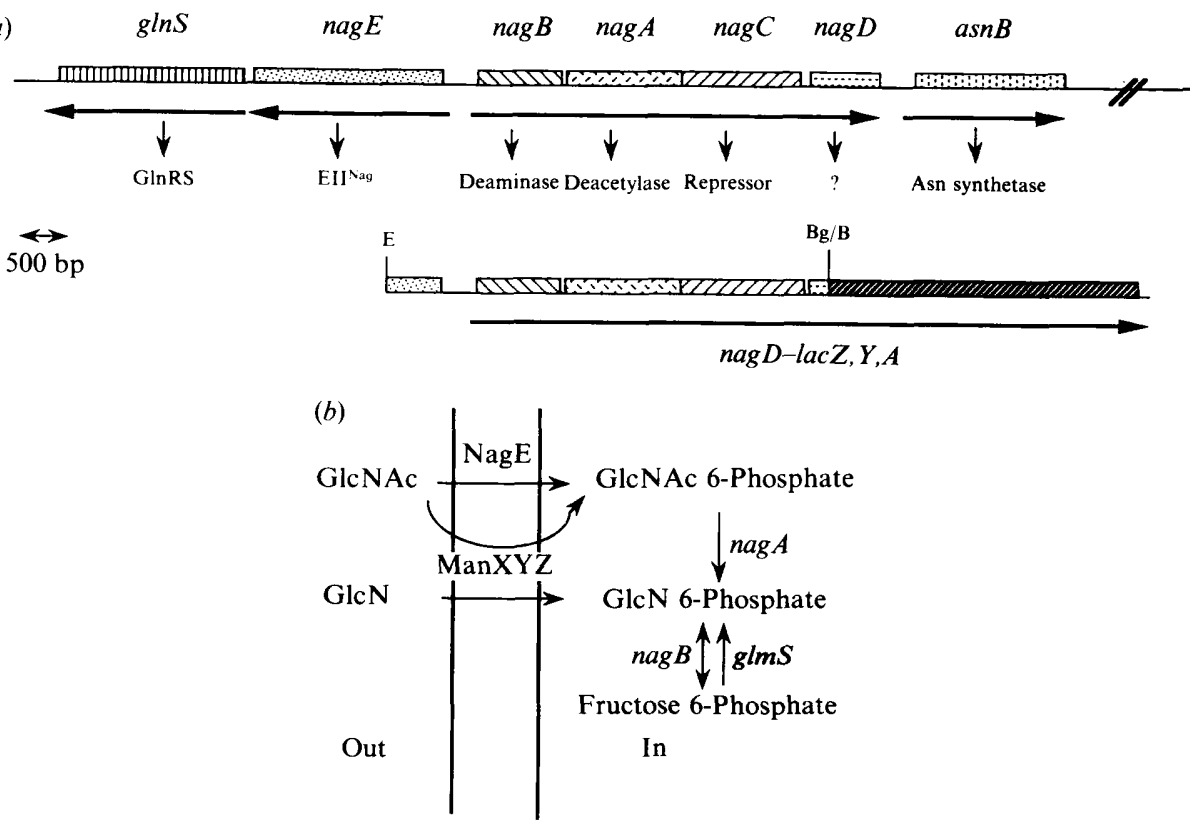

Fig. 1. Organisation of the chromosome in the vicinity of the nag genes and the metabolism of GlcNAc. (a) Location of the nag genes and their direction of transcription, together with that of the surrounding genes; $g \ln S$, encoding glutaminyl-tRNA synthetase (GlnRS) and asn $B$, encoding asparagine synthetase. The transposon $z b f 507:: \operatorname{Tn} 10$ is located on the clockwise-side of the genes (right on the figure). Underneath is shown the structure of the nagD-lacZ fusion carried by $\mathrm{pEBg} 1$ and $\mathrm{pEBgN} 4$. B, BamHI; $\mathrm{Bg}$, $B g I I I ; E, E c o$ RI. (b) Scheme showing the metabolism of GlcNAc and GlcN and the functions of the nag genes. $\mathrm{glmS}$ encodes glucosamine synthetase but the normally catabolic nag $B$ gene product can also function anabolically under certain conditions (Vogler et al., 1989).

mutations. The strain carrying the nagAl mutation, JP5053, available from the CGSC (E. coli Genetic Stock Center, Yale University, New Haven, CT, USA) is of this type, it does not grow on GlcNAc, grows very slowly on GlcN and is insensitive to GlcNAc in the medium. This paper describes the analysis of the strain carrying the nagAl mutation and identifies the secondary mutation as a mutation in the nagC gene giving a superrepressor phenotype.

\section{Methods}

Bacteriological methods. The E. coli strains used in this work are listed in Table 1 . The nag $B^{\prime}-$ lac $Z$ fusion carried by a $\lambda c / 857$ transducing phage, $\lambda \mathrm{NagB}-\mathrm{lacZ}$, and its use in measuring expression of the nag regulon have been described previously (Plumbridge, 1990). The same fusion transferred to a $\mathrm{cI}^{+} \mathrm{imm}^{21}$ bacteriophage ( $\lambda \mathrm{RS45}$ ) by the method of Simons et al. (1987) is called $\lambda R S / N a g B-l a c Z$. $\beta$-Galactosidase activities, expressed in the units described by Miller (1972) are the average of four samples per bacterial culture taken at two different optical densities. Generally, several independent cultures were measured and the results differed by less than $10 \%$. Bacteria were grown at $30^{\circ} \mathrm{C}$ in minimal MOPS medium (Neidhardt et al., 1974) supplemented with $50 \mu \mathrm{g}$ arginine and histidine $\mathrm{ml}^{-1}$ and $0.2 \%$ carbon source, except glycerol which was $0.4 \%$. Cultures of bacteria carrying plasmids were grown in MOPS medium with $0.5 \%$ Casamino acids and $500 \mu \mathrm{g}$ ampicillin $\mathrm{ml}^{-1}$. $\mathrm{Nag}^{\mathrm{S}}$ was conveniently monitored on MacConkey-GlcNAc plates. $\mathrm{Nag}^{+}$colonies are red, $\mathrm{Nag}^{-}$colonies are white, while Nags bacteria do not grow. Loss of the transposon Tn10 was selected as described by Maloy \& Nunn (1981).

Recombinant DNA techniques. The $4.2 \mathrm{~kb}$ EcoRI-BglI fragment of pB30-1 (Plumbridge, 1989) carrying the 5 end of nagE, nagBAC and the beginning of nagD (Fig. 1) was cloned into the lacZ fusion vector pMC1403 (Casadaban et al., 1980), digested with EcoRl and BamHI, and the ligated mixture transformed into IBPC574 (nag A1, nagC11). Since the $\operatorname{lac} Z$ gene at the BamHI site is in the same phase as the nagD gene at the $B g I I I$ site, the resulting colonies were expected to be blue on $\mathrm{X}$-gal-containing plates and since the plasmid insert carried the nag $A$ gene, the plasmids were expected to complement the nag $A 1$ mutation and produce $\mathrm{Nag}^{+}$bacteria. Some of the blue clones were however $\mathrm{Nag}^{-}$, e.g. IBPC574(pEBgl), while others were $\mathrm{Nag}^{+}$. Restriction enzyme analysis of the plasmid DNA showed that the plasmids conferring either a $\mathrm{Nag}^{+}$or $\mathrm{Nag}^{-}$phenotype contained the same DNA insert. When the transformation was repeated in the nag $^{+}$strain IBPC5321 all the resulting $\mathrm{Lac}^{+}$colonies were $\mathrm{Nag}^{+}$, e.g. IBPC574(pEBgN4)). The plasmids conferring $\mathrm{Nag}^{+}$and $\mathrm{Nag}^{-}$phenotypes were cycled through a recAl strain, wild-type for nag, and retested for their ability to complement the nagAl mutation in IBPC574CR. The plasmid inserts were transfered to $\lambda \mathrm{RS} 45$ to give $\lambda \mathrm{EBg} 1$ and $\lambda \mathrm{EBgN} 4$. The nag $A$ and nagC genes from $\mathrm{pEBg} 1$ were subcloned to $\mathrm{pUC19}$ and pBR322 as described for the wild-type proteins (Plumbridge, 1989). In pBR322 only low levels of the cloned genes are expressed in the absence of the pUC19 lac promoter. The same fragments were cloned into M13mp18 and M13mp19 and sequenced using Sequenase (US Biochemicals) and $\left[\alpha^{35}\right.$ S thio-dATP.

A chromosomal replacement of the whole nag region between HpaI sites in $n a g E$ and $a s n B$ with a tetracycline resistance (tc) cassette was constructed using the $\operatorname{recBC} s b c B C$ strain JC7623 (Jasin \& Schimmel, 1984) to give strain IBPC590 as described previously for the nagE, $B, A$, $C$ and D insertion mutations (Plumbridge, 1991).

\section{Results and Discussion}

\section{Localization of the mutation conferring $\mathrm{Nag}^{R}$ in the nag $A 1$ strain}

The nagA1 mutation was transduced out of JP5053 using the Tn 10 marker $z b f 507:: \operatorname{Tn} 10$, which is about $50 \%$ cotransducible with the nag region, into the $\Delta l a c$ strain 
Table 1. Bacterial strains

\begin{tabular}{|c|c|c|}
\hline Strain* & Relevant genotype & Reference or source \\
\hline $\begin{array}{l}\text { JP5053 } \\
\text { JP5061 }\end{array}$ & $\begin{array}{l}\text { argH1 metB1 nagAl nagC11 rpsL155 rpoB352 } \lambda^{\mathrm{R}} \lambda^{+} \\
\text {thi-1 leuB6 purE42 nagB2 galE45 mtl-1 xyl-5 ara-14 } \\
\text { rpsL109 azi-6? rpoB301 tonA23 tsx-67 supE44 }\end{array}$ & $\begin{array}{l}\text { B. Bachmann, CGSC } \\
\text { B. Bachmann, CGSC }\end{array}$ \\
\hline IBPC5321 & thi-1 argG6 argE3 his-4 mtl-1 xyl-5 rpsL tsx-29? $\triangle$ lacX74 & Plumbridge (1989) \\
\hline IBPC574 & IBPC5321 nagAl nagC11 zbf507::Tn10 & Plumbridge (1989) \\
\hline IBPC574C & IBPC5321 nagAl nagC11 & \\
\hline IBPC524 & IBPC5321 nag $A:: \mathrm{cml}$ & Plumbridge (1991) \\
\hline IBPC531 & IBPC5321 nag $A:: \mathrm{cm} 2$ & Plumbridge (1991) \\
\hline IBPC529C & IBPC5321 nagC:: $\mathrm{cm}$ & Plumbridge (1991) \\
\hline IBPC590 & IBPC5321 $\Delta$ nag $E B A C D::$ tc & This work \\
\hline IBPC424 & IBPC5321 $g \ln S 1 \sup E 44$ & Plumbridge \& Söll (1989) \\
\hline IBPC527 & Similar to IBPC 524 & \\
\hline IBPC527-1S & $\mathrm{Nag}^{\mathrm{R}}$ derivative of IBPC 527 & \\
\hline IBPC583 & IBPC5321 nag $E:: \mathrm{km}$ nag $A:: \mathrm{tc}$ & This work \\
\hline IBPC711 & IBPC5321 nagAl $\lambda \mathrm{RS} / \mathrm{NagB}-\mathrm{lacZ}$ & This work \\
\hline IBPC712 & IBPC5321 glnS1 nagC11 zbf507::Tn10 $\lambda$ RS/NagB-lacZ & This work \\
\hline JM101 nnag & JM101 AnagEBACD::tc & This work \\
\hline
\end{tabular}

* The letter $\mathrm{R}$ after a strain number (e.g. IBPC574CR) indicates the recAl derivative of the strain, normally constructed by P1-mediated co-transduction with the adjacent $s r l:: \operatorname{Tn} 10$ marker.

Table 2. The effect of the nagAI nagC11 mutations on activation of the nag regulon

The bacterial strains indicated, carrying the $\lambda \mathrm{NagB}-\mathrm{lacZ}$ fusion to monitor the activity of the nag regulon, were grown continuously in minimal MOPS medium with the carbon sources indicated and $\beta$-galactosidase activity, expressed in units described by Miller (1972), was measured as described in Methods. The values given are the mean of at least two independent cultures. Three transductants of the type IBPC712, but only one isolate of the type IBPC711, were found (Table 5) and tested. Strain IBPC712 carries in addition the $g \operatorname{lnS} 1$ (ts) mutation.

\begin{tabular}{llccccc}
\hline \hline & \multicolumn{5}{c}{$\beta$-Galactosidase activity of the $\lambda$ NagB-lacZ fusion } \\
\cline { 3 - 7 } Strain & Genotype & Glucose & $\begin{array}{c}\text { Glucose } \\
\text { +GlcNAc }\end{array}$ & Glycerol & $\begin{array}{c}\text { Glycerol } \\
+ \text { GlcNAc }\end{array}$ & GicN \\
\hline IBPC5321 & Wild-type & 55 & 630 & 81 & 1090 & 295 \\
IBPC574 & nagA1 nagC11 & 57 & 55 & 120 & 87 & 130 \\
IBPC711 & nagA1 nagC & 1550 & ND & ND & 2370 & ND \\
IBPC712 & nagA $A^{+}$nagC11 & 35 & ND & ND & 38 & ND \\
\hline \hline
\end{tabular}

ND, Not determined.

IBPC5321. The resulting strains (e.g. IBPC574) all had the same characteristics as JP5053; they were $\mathrm{Nag}^{-}$, $\mathrm{Nag}^{\mathrm{R}}$ and grew very slowly on GlcN (doubling time 5$6 \mathrm{~h}$ compared to $100 \mathrm{~min}$ for IBPC5321 at $37^{\circ} \mathrm{C}$ ). It was apparent, therefore, that the mutations causing the $\mathrm{Nag}^{-}$ and $\mathrm{Nag}^{\mathrm{R}}$ phenotypes had co-transduced into IBPC574. The growth defects were complemented by plasmids carrying the entire nagBACD operon, e.g. pB30-1, but not by a plasmid expressing just nag $A$ [pBR(NagA)], which complements an in vitro-constructed null mutation in nag $A$, nag $A:: \mathrm{cm}$ (Plumbridge, 1991). This suggested that a mutation within the nag operon but outside $\operatorname{nag} A$ is responsible for the $\mathrm{Nag}^{\mathrm{R}}$ phenotype. Expression of the $\lambda \mathrm{NagB}-\mathrm{lacZ}$ fusion in IBPC574 was very low and addition of GlcNAc to a culture growing on glucose or glycerol failed to increase the expression (Table 2) showing that the secondary mutation was acting in trans on expression of the NagB-lacZ fusion. These properties of the secondary mutation are consistent with a superrepressor mutation in the nagC gene. The experiments described below, confirmed this interpretation and the mutation has been named nagC11. 
Table 3. Effect of the nagAl nagC11 mutations on growth on GlcN and GlcNAc in diploids

The table gives the doubling times at $30^{\circ} \mathrm{C}$ in minimal MOPS medium containing $50 \mu \mathrm{g}$ arginine and histidine $\mathrm{ml}^{-1}$ and $0.2 \%$ of the carbon sources indicated. The strains are all diploid for the nag region and the alleles carried by the chromosome and the $\lambda$ lysogen are indicated. Strains were precultured in the same medium overnight and diluted to give a starting $O D_{650}$ of about 0.02 , and growth was followed spectroscopically until $\mathrm{OD}_{650}=0.5$. The values given are the average of two independent experiments for growth on GICNAc or GICN. They differed by less than $12 \%$ (for the slow growth rates) and most by less than $5 \%$.

\begin{tabular}{|c|c|c|c|c|c|}
\hline \multirow[b]{2}{*}{ Strain } & \multicolumn{2}{|c|}{ Genotype } & \multicolumn{3}{|c|}{$\begin{array}{l}\text { Doubling times for growth } \\
\text { on carbon source } \\
(\mathrm{min})\end{array}$} \\
\hline & Chromosome & Lysogen & Glucose & GlcN & GlcNAc \\
\hline $\begin{array}{l}\text { IBPC574CR( }(\lambda E B g 1) \\
\text { IBPC574CR( } \lambda E B g N 4) \\
\text { IBPC524R( } \lambda E B g 1) \\
\text { IBPC524R( }(\lambda E B g N 4) \\
\text { IBPC5321R( }(\lambda E B g 1) \\
\text { IBPC5321R( }(\lambda E B g N 4)\end{array}$ & 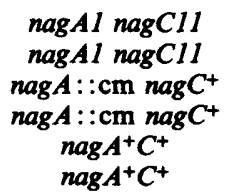 & 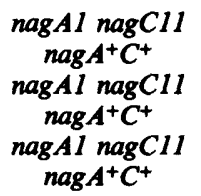 & $\begin{array}{l}86 \\
88 \\
82 \\
77 \\
82 \\
85\end{array}$ & $\begin{array}{l}580 \\
255 \\
190 \\
120 \\
265 \\
145\end{array}$ & $\begin{array}{r}\text { NG } \\
340 \\
\text { NG } \\
83 \\
270 \\
89\end{array}$ \\
\hline
\end{tabular}

NG, No growth.

Effect of the nagA1 nagC11 mutations in cells diploid for the nag region

The nag $A 1$ nagC11 mutations were cloned by homologous recombination to give plasmid $\mathrm{pEBg} 1$ and bacteriophage $\lambda \mathrm{EBg} 1$ as described in Methods. pEBgN4 and $\lambda \mathrm{EBgN} 4$ carry the equivalent wild-type DNA. Three strains were lysogenized with $\lambda \mathrm{EBg} 1$ and $\lambda \mathrm{EBgN} 4:$ IBPC5321R (wild-type for nag), IBPC574CR (nagA1 nagC11) and IBPC524R carrying a null mutation in the nag $A$ gene. Analysis of the growth rates (Table 3) of the six diploid strains showed that the mutations conferring both the $\mathrm{Nag}^{-}$and the $\mathrm{Nag}^{\mathrm{R}}$ character were present on $\lambda \mathrm{EBgl}$. IBPC574CR( $\lambda \mathrm{EBg} 1)$, the homozygous nagAl nagC11/ nagAl nagC11 diploid grew very slowly on GlcN (doubling time about $580 \mathrm{~min}$ ) and not at all on GlcNAc. For both the heterozygous $\operatorname{nagAl} \operatorname{nagC11} / \operatorname{nag} \mathrm{A}^{+} \mathrm{C}^{+}$ diploids IBPC5321 ( $\lambda \mathrm{EBg} 1)$ and IBPC574CR( $\lambda \mathrm{EBgN} 4)$, growth rates on both GlcN and GlcNAc were slower, two- and three-fold, respectively, than with the wild-type nag $A^{+} C^{+} / n a g A^{+} C^{+}$diploid showing the dominant nature of the nagAl nagC11 mutations which act in trans on the expression of the wild-type operon. The presence of the nag $A:: \mathrm{cm}$ allele had no effect on the activity of the wildtype nag genes, IBPC524R( $\lambda \mathrm{EBgN} 4)$ grew normally on GlcNAc and GlcN. However, the nagA :: $\mathrm{cm} \mathrm{nagC} C^{+}$ nag $A 1$ nagC11 diploid, IBPC524R( $\lambda \mathrm{EBg} 1)$, did not grow on GlcNAc and grew slowly on GlcN. All the strains grew identically on glucose (Table 3 ).

\section{Effect of individually cloned nagA1 and nagC11 alleles}

The nag $A$ and nagC genes were cloned from $\mathrm{pEBg} 1$ into pUC19 and pBR322. The cloned nagAl allele complemented neither the nag $A 1$ nor the nag $A:: \mathrm{cm}$ mutations. The effect of the individual nag $I I$ and nagC1I alleles on expression of the nag regulon was tested by measuring their effect on the $\lambda \mathrm{NagB}-\mathrm{lacZ}$ fusion and their ability to complement null mutations in the nag $A$ and nagC genes (Table 4). Disruption of either nag A (IBPC531R) or nagC (IBPC529CR) by insertion of a $\mathrm{Cm}^{\mathrm{R}}$ cassette produces a derepression of the regulon (Table 4, row 1 ) which is complemented by the cloned wild-type nag $A$ or nagC genes, respectively (Table 4, rows 2 and 4; Plumbridge, 1991). The cloned nagAI allele has no effect on the derepression provoked by an insertion in nag $A$ (or nagC) (Table 4, row 5). This is consistent with the mutation producing a non-functional protein. On the other hand the cloned nagCl1 allele not only complements the derepression provoked by the nagC:: $\mathrm{cm}$ mutation but also complements the derepression produced by the nag $A:: \mathrm{cm}$ mutation or a deletion of the nagEBACD genes, which the wild-type nag $C$ gene cannot do (Table 4, rows 2 and 3). Derepression of the nagA ::cm strain is due to the accumulation of the inducer GlcNAc 6phosphate which cannot be degraded in the absence of an active GlcNAc-6-phosphate deacetylase encoded by nagA (Plumbridge, 1991). Strains carrying the nagA1 nagC11 mutation accumulate high levels of GlcNAc 
Table 4. Effect of the cloned nagAl and nagC11 alleles on expression of the nag regulon

\begin{abstract}
The bacterial strains indicated, lysogenized with $\lambda \mathrm{NagB}-$ lacZ to monitor activity of the nag regulon, were transformed with the five $\mathrm{pBR} 322$-derived plasmids. $\mathrm{pBR}(\mathrm{NagA})$ and $\mathrm{pBR}(\mathrm{NagC})$ are plasmids expressing low levels of the wild-type proteins. pBR(NagAl) and pBR(NagC11) are the equivalent plasmids carrying the cloned mutant alleles from pEBg1. The transformants were grown continuously in minimal MOPS medium with the carbon sources indicated, supplemented with $0.5 \%$ Casamino acids and $500 \mu \mathrm{g}$ ampicillin $\mathrm{ml}^{-1}$. The table gives the $\beta$-galactosidase activities expressed in units described by Miller (1972) from a representative experiment.
\end{abstract}

\begin{tabular}{|c|c|c|c|c|c|}
\hline \multirow[b]{2}{*}{$\begin{array}{l}\text { Strain (IBPC): } \\
\text { Genotype: } \\
\text { Grown on: }\end{array}$} & \multicolumn{5}{|c|}{$\beta$-Galactosidase activities of the $\lambda \mathrm{NagB}$-lacZ fusion } \\
\hline & $\begin{array}{c}\text { 5321R } \\
\text { Wild-type } \\
\text { Glucose }\end{array}$ & $\begin{array}{c}\text { 5321R } \\
\text { Wild-type } \\
\text { GlcNAc }\end{array}$ & $\begin{array}{c}\text { 529CR } \\
\text { nagC::cm } \\
\text { Glucose }\end{array}$ & $\begin{array}{c}531 \mathrm{R} \\
\text { nagA::cm } \\
\text { Glucose }\end{array}$ & $\begin{array}{c}590 \\
\Delta \text { nagEBACD } \\
\text { Glucose }\end{array}$ \\
\hline \multicolumn{6}{|l|}{ Plasmid } \\
\hline pBR322 & 61 & 840 & 1120 & 1145 & 1170 \\
\hline pBR(NagC) & 34 & 695 & 35 & 1260 & 1012 \\
\hline pBR(NagC11) & 23 & 167 & 25 & 51 & 30 \\
\hline pBR(NagA) & 42 & 435 & 1050 & 60 & 1171 \\
\hline pBR(NagA1) & 66 & 770 & 1005 & 1200 & 1032 \\
\hline
\end{tabular}

6-phosphate as observed for the nag $A:: \mathrm{cm}$ strain (Plumbridge, 1991) and the original nagAI isolate (White, 1968). The nagCl protein is apparently insensitive to this inducer and can bind to the nag operators and repress in the presence of high levels of GlcNAc 6-phosphate present in the nag $A$ strains.

The insensitivity of the mutant repressor to GlcNAc 6phosphate was confirmed by an in vitro test (Fig. 2). Both the wild-type (lanes 2-5) and NagCll (lanes 6-9) repressors form complexes with nag DNA under similar conditions as visualized by gel mobility shift assay, but only the wild-type repressor is dissociated by the presence of GlcNAc 6-phosphate (lanes 10-12) whilst the NagC11 complex is unaffected (lanes 13-15).

The identification of the NagCll mutation as one producing an inducer-insensitive super-repressor, permitted a genetic selection for the separated mutations nagAl and nagC11 based on their effect on the $\lambda \mathrm{NagB}$ lacZ fusion (Table 5). The NagB-lacZ fusion in strain IBPC711 ( $\operatorname{nagA1}$ nagC $^{+}$) was derepressed while that in IBPC712 (nag $A^{+}$nagC11) was uninducible (Table 2).

Sequencing the cloned inserts of $\mathrm{pBR}(\mathrm{NagAl})$ and pBR(NagC11) located two point mutations. The nagA1 mutation resulted in a change from Asp to Asn (GAT to AAT) at position 248 (total 382) and the nagC11 mutation resulted in a change from Leu to Pro (CTG to CCG) at position 125 (total 406). It is interesting to note that the nagAl mutation, a +1 charge change, results in a protein with an apparent molecular mass on SDSpolyacrylamide gels more in agreement with the molecular mass predicted by the DNA sequence $(41.9 \mathrm{kDa})$ than the wild-type protein which migrates with an apparent molecular mass of $44 \mathrm{kDa}$ (Plumbridge, 1989).

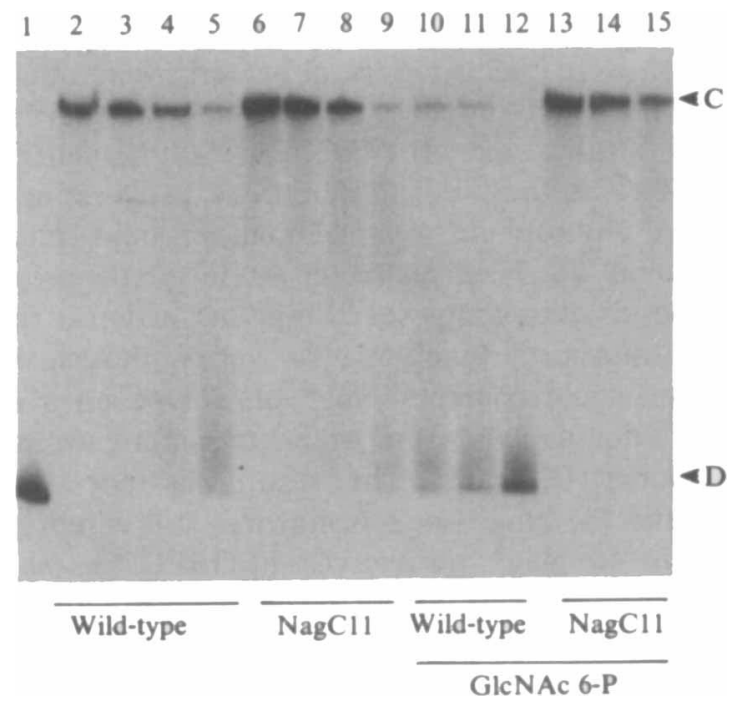

Fig. 2. Insensitivity of the NagC11 protein to inducer, GlcNAc 6phosphate. Complexes between nag DNA and the wild-type or NagC11 repressor were detected by gel retardation as described previously (Plumbridge \& Kolb, 1991). JM101 nag carrying either pUC(NagC) or pUC(NagC11) was grown in LB plus $500 \mu \mathrm{g}$ ampicillin $\mathrm{ml}^{-1}$ and induced for $3 \mathrm{~h}$ with $1 \mathrm{mM}$-IPTG to overproduce the repressor. Extracts were sonicated, clarified by centrifugation, adjusted to $10 \mathrm{mg}$ protein $\mathrm{ml}^{-1}$ and tested for DNA binding on a $200 \mathrm{bp}$ fragment covering the intergenic nag $E-B$ region uniformly labelled with $\left[\alpha^{32} \mathrm{P}\right] \mathrm{dCTP}$. Dilutions of the extracts were mixed with DNA in 25 mM-HEPES, 100 mM-sodium glutamate buffer (pH 8.0) containing $500 \mu \mathrm{g} \mathrm{BSA} \mathrm{ml}^{-1}, 200 \mu \mathrm{M}$-cAMP and $5 \mathrm{mM}$-GlcNAc 6-phosphate where indicated. After $15 \mathrm{~min}$ at room temperature the complexes were analysed on a $5 \%(w / v)$ acrylamide gel. The figure shows an autoradiograph of the dried gel. Lanes: 1 , free DNA; 2-5 and 10-12, extract from pUC(NagC); 6-9 and 13-15, extract from pUC(NagC11). Protein concentrations due to the bacterial extracts are $100 \mu \mathrm{g} \mathrm{ml}^{-1}$ (lanes 2, 6, 10 and 13), $50 \mu \mathrm{g} \mathrm{ml}^{-1}$ (lanes 3, 7, 11 and 14), $25 \mu \mathrm{g} \mathrm{ml}^{-1}$ (lanes 4, 8, 12 and 15) and 12.5 $\mu \mathrm{g} \mathrm{ml}^{-1}$ (lanes 5 and 9). Arrowheads indicate the migration positions of free-nag DNA (D) and the complex nag DNA-cAMP/CAP-NagC (C). 
Table 5. Cotransduction frequencies between $g \ln S$, nagA, nagC and zbf507::Tn10

\begin{tabular}{|c|c|c|c|c|}
\hline \multicolumn{2}{|c|}{ Strain } & \multicolumn{2}{|c|}{ Marker } & \multirow{2}{*}{$\begin{array}{c}\text { Co-transduction } \\
(\%)\end{array}$} \\
\hline Donor & Recipient & Selected & Unselected & \\
\hline & & $g \ln S^{+}$ & $\begin{array}{l}\text { zbf507:: } \operatorname{Tn} 10 \\
\text { nagA1 nagCl1 } \\
\text { nagA1 nagC } C^{+} \ddagger\end{array}$ & $\begin{array}{l}51(53 / 103) \\
85(87 / 103) \\
0.4(1 / 260)\end{array}$ \\
\hline
\end{tabular}

* Phenotype; $\mathrm{Nag}^{-}$, uninducible.

† Phenotype; very slow growth on GlcNAc, NagB-lacZ fusion repressed, resulting strain called IBPC712.

$\ddagger$ Phenotype; $\mathrm{Nag}^{-}$, NagB-lacZ fusion derepressed, resulting strain called IBPC711.

\section{Other mutations resulting in a Nag ${ }^{\mathrm{R}}$ phenotype}

$\mathrm{Nag}^{\mathrm{R}}$ derivatives of strains carrying the $\operatorname{nag} A:: \mathrm{cm}$ mutation were selected. Several bacteria were obtained which exhibited properties different from the nagAl nagC11 strains, e.g. IBPC527-1S: in particular the $\mathrm{NagB}-\mathrm{lacZ}$ fusion was still derepressed suggesting that GlcNAc 6-phosphate was accumulating and inducing the regulon. The $\mathrm{Nag}^{\mathrm{R}}$ character was lost in the presence of plasmids expressing $n a g E$ implying a defect in the $n a g E$ (transport) function. To verify that a $n a g E$ mutation could confer a $\mathrm{Nag}^{\mathrm{R}}$ phenotype on a nagA strain, a double $n a g E:: \mathrm{km} \operatorname{nag} A::$ tc mutant strain was constructed (IBPC583). This strain was indeed $\mathrm{Nag}^{-}$ $\mathrm{Nag}^{\mathrm{R}}$ and the NagB-lacZ fusion was still derepressed. Analysis of $\mathrm{Nag}^{\mathrm{R}}$ derivatives of IBPC711 (nagAl) identified a third class where the deacetylase activity has been partially or fully restored which prevents the intracellular accumulation of the inducer, GlcNAc 6phosphate.

It should be noted that the nagC11 super-repressor mutation is not a new class of mutation. Mis-sense mutations in the lacI gene coding for the Lac repressor, which produce super-repressor phenotypes, have been known for a long time (reviewed in Miller, 1980). Recently Kleina \& Miller (1990) have detected additional amino acid substitutions in the Lac repressor using an elegant system of complementation of amber mutations with suppressors inserting many different amino acids. Other examples of super-repressor phenotypes have been described: e.g. gal (Saedler et al., 1968), trp (Kelley \& Yanofsky, 1985), $\lambda$ (Hecht \& Sauer, 1985), Tn10tet (Smith \& Bertrand, 1988), fadR (Hughes et al., 1988) and nadI (Zhu \& Roth, 1991).

The complete insensitivity of the nagC11 protein to inducer and its strongly inhibitory effect when present in a diploid could be indicative that the mutation is directly affecting the GlcNAc 6-phosphate binding site. However, it is to be admitted that the change from Leu to Pro at position 125 in nagCl could produce a major structural change in the protein, for example preventing the allosteric transition to the form inactive in DNA binding. As yet nothing is known about the structural domains in the Nag repressor. A helix-turn-helix DNA binding motif was tentatively identified in the Cterminal part of the protein (Plumbridge, 1989). The mutation at amino acid 125, about one third of the way from the $\mathrm{N}$-terminal, could locate another functional domain.

I thank Annie Kolb and Hilde de Reuse for useful discussions and comments on the manuscript, and Barbara Bachmann for the gift of bacterial strains. This work was performed in the laboratory of Marianne Grunberg-Manago whose interest is gratefully appreciated and was supported by grants from the CNRS, INSERM, the EEC, the Fondation pour la Recherche Médicale and Université Paris 7.

\section{References}

BACHMANN, B. J. (1990). Linkage map of Escherichia coli K12, edition 8. Microbiological Reviews 54, 130-197.

BERNHEIM, N. J. \& Dobrogosz, W. J. (1970). Amino sugar sensitivity in Escherichia coli mutants unable to grow on $N$-acetylglucosamine. Journal of Bacteriology 101, 384-391.

Casadaban, M. J., Chou, J. \& Cohen, S. N. (1980). In vitro gene fusions which join an enzymatically active $\beta$-galactosidase segment to amino-terminal fragments of exogenous proteins: Escherichia coli plasmids vectors for the detection and cloning of translational initiation signals. Journal of Bacteriology 143, 971-980.

CURTIS, S. J. \& EPSTEIN, W. (1975). Phosphorylation of D-glucose in $E$. coli mutants defective in glucosephosphotransferase, mannosephosphotransferase and glucokinase. Journal of Bacteriology 122, 11891199.

ERni, B., Zanolari, B. \& Kocher, H. P. (1987). The mannose permease of $E$. coli consists of three different proteins. Journal of Biological Chemistry 262, 5238-5247.

HeChT, M. H. \& SAUER, R. T. (1985). Phage lambda repressor revertants: amino acid substitutions that restore activity to mutant proteins. Journal of Molecular Biology 186, 53-63. 
Holmes, R. P. \& Russell, R. R. B. (1972). Mutations affecting amino sugar metabolism in Escherichia coli K12. Journal of Bacteriology 111 , 290-291.

Hughes, K. T., Simons, R. W. \& NuNN, W. D. (1988). Regulation of fatty acid degradation in Escherichia coli: fadR superrepressor mutants are unable to utilise fatty acids as sole carbon source. Journal of Bacteriology 170, 1666-1671.

JASIN, M. \& SCHIMMEL, P. (1984). Deletion of an essential gene in Escherichia coli by site specific recombination with linear DNA fragments. Journal of Bacteriology 159, 783-786.

JONES-MORTIMER, M. C. \& KoRNBERG, H. L. (1980). Amino-sugar transport systems in Escherichia coli K12. Journal of General Microbiology 117, 369-376.

KelleY, R. L. \& YANOFSKY, C. (1985). Mutational studies with the trp repressor of Escherichia coli support the helix-turn-helix model of repressor recognition of operator DNA. Proceedings of the National Academy of Sciences of the United States of America 82, 483-487.

Kleina, L. G. \& Miller, J. H. (1990). Genetic studies of the lac repressor. XIII. Extensive amino acid replacements generated by the use of natural and synthetic nonsense suppressors. Journal of Molecular Biology 212, 295-318.

LENGELER, J. (1980). Characterisation of mutants of Escherichia coli $\mathrm{K} 12$, selected by resistance to streptozotocin. Molecular and General Genetics 179, 49-54.

Maloy, S. R. \& NuNN, W. D. (1981). Selection for loss of tetracycline resistance by Escherichia coli. Journal of Bacteriology 145, 1110-1112.

MiLler, J. H. (1972). In Experiments in Molecular Genetics. Cold Spring Harbor, New York: Cold Spring Harbor Laboratory.

MiLleR, J. H. (1980). In The Operon, pp. 31-88. Edited by J. H. Miller \& N. S. Reznikoff. Cold Spring Harbor, New York: Cold Spring Harbor Laboratory.

NeidhardT, F. C., Bloch, P. L. \& Smith, D. F. (1974). Culture medium for enterobacteria. Journal of Bacteriology 119, 736-747.

PERI, K. G. \& WAYGOOD, E. B. (1988). Sequence of cloned EnzymelI ${ }^{\text {Nag }}$ of the phosphoenolpyruvate: $N$-acetylglucosamine phosphotransferase system of Escherichia coli. Biochemistry 27, 60546061 .

Plumbridge, J. A. (1989). Sequence of the nagBACD operon in Escherichia coli $\mathrm{K} 12$ and pattern of transcription within the nag regulon. Molecular Microbiology 3, 506-515.

Plumbridge, J. A. (1990). Induction of the nag regulon of Escherichia coli by $\mathrm{N}$-acetylglucosamine and glucosamine: Role of the cAMP- catabolite activator protein complex in expression of the regulon. Journal of Bacteriology 172, 2728-2735.

PLUMBRIDGe, J. A. (1991). Repression and induction of the nag regulon of Escherichia coli $\mathrm{K} 12$ : the roles of nagC and nag $A$ in maintenance of the uninduced state. Molecular Microbiology 5, 2053-2062.

Plumbridge, J. A. \& Kolb, A. (1991). CAP and Nag repressor binding to the regulatory regions of the nagE-B and $\operatorname{man} X$ genes of $E$. coli. Journal of Molecular Biology 217, 661-679.

Plumbridge, J. A. \& SölL, D. (1989). Characterisation of cis-acting mutations which increase the expression of a $g \ln S$-lac $Z$ fusion in Escherichia coli. Molecular and General Genetics 216, 113-119.

Rogers, M. J., Ohgi, T., Plumbridge, J. A. \& Söll, D. (1988). Nucleotide sequences of the Escherichia coli nag $E$ and nagB genes: the structural genes for the $\mathrm{N}$-acetylglucosamine transport protein of the bacterial phosphoenolpyruvate:sugar phosphotransferase system and for glucosamine-6-phosphate deaminase. Gene 62, 197-207.

Saedler, H., Guillon, A., Fiethen, L. \& Starlinger, P. (1968). Negative control of the galactose operon of E. coli. Molecular and General Genetics 102, 79-88.

SARIS, P. E. J. \& Palva, E. T. (1987). The ptsL, pel/ptsM (manXYZ) locus consists of three genes involved in mannose uptake in $E$. coli. FEMS Microbiology Letters 44, 371-376.

SimONS, R. W., HoumAN, F. \& KLECKNER N. (1987). Improved single and multicopy lac based cloning vectors for protein and operon fusions. Gene 53, 85-96.

Smith L. D. \& Bertrand, K. P. (1988). Mutations in the Tn10 tet repressor that interfere with induction: location of the tetracyclinebinding domain. Journal of Molecular Biology 203, 949-959.

VOGLER, A. P. \& LENGELER, J. W. (1989). Analysis of the nag regulon from Escherichia coli $\mathrm{K} 12$ and Klebsiella pneumoniae and of its regulation. Molecular and General Genetics 219, 97-105.

Vogler, A. P., Trentman, S. \& Lengeler, J. W. (1989). Alternative route for biosynthesis of amino sugars in $E$. coli $\mathrm{K} 12$ mutants by means of a catabolic isomerase. Journal of Bacteriology 171, 65826592.

WHITE, R. J. (1968). Control of aminosugar metabolism in Escherichia coli and isolation of mutants unable to degrade amino sugars. Biochemical Journal 106, 847-858.

ZHU, N. \& RoTH, J. R. (1991). The nadI of Salmonella typhimurium encodes a bifunctional regulatory protein. Journal of Bacteriology 173, 1302-1310. 